\title{
The regulation of competition in the National Health Service (NHS): what difference has the Health and Social Care Act 2012 made?
}

\author{
MARIE SANDERSON* \\ Research Fellow, London School of Hygiene and Tropical Medicine, London, UK \\ PAULINE ALLEN \\ Reader, London School of Hygiene and Tropical Medicine, London, UK \\ DOROTA OSIPOVIC \\ Research Fellow, London School of Hygiene and Tropical Medicine, London, UK
}

\begin{abstract}
This article examines the impact of the Health and Social Care Act 2012 on the regulation of competition in the English National Health Service (NHS), by focussing on the change it marked from a system of sector-specific regulation to one which is clearly based in competition law. It has been suggested that the Act and its associated reforms would significantly alter accountability in the NHS, and would change decisions from the remit of public policy to that of the law. To assess the impact the Act has had in practice, the article compares the interpretation of the rules regarding competition in the NHS by the regulators of competition immediately before, and following, the passing of the Act. It argues that, whilst the reforms have the potential significantly to alter the way competition in the NHS is regulated, the impact of the reforms in this area is limited by the development of systems within the NHS to manage and resolve issues internally where possible.
\end{abstract}

Submitted 14 October 2015; revised 10 February 2016; accepted 15 February 2016; first published online 28 March 2016

\section{Introduction}

In common with many Organisation for Economic Co-operation and Development (OECD) countries, the National Health Service (NHS) in England has a long-standing interest in the use of incentives for competition in the provision of services. An important accompaniment to the development of competition is the development of rules to govern behaviour. In the case of the English NHS, these rules consist of both legislation (primary, i.e. acts of parliament; and secondary, i.e. statutory instruments) 
and policies issued by the Department of Health and NHS England. A significant change in the regulation of competition in the English NHS occurred when the Health and Social Care Act 2012 (HSCA 2012) came into force on 1 April 2013. Whilst the reforms of HSCA 2012 in many ways continued the direction of travel for the incentivisation of competition in the English NHS, the legislation significantly altered the regulation of competition through the clear extension of competition law to apply to the planning and provision of NHS services. The implications of this increased emphasis on the rule of law in the regulation of NHS competition are the focus of this paper. As shall be explored in further detail below, before HSCA 2012, the connection between NHS competition and competition law was largely theoretical. Competition in the NHS was regulated through compliance with sector-specific rules monitored by bodies within the NHS hierarchy. HSCA 2012 altered this internally focussed arrangement by recasting the sector-specific rules in a legal framework, making an explicit connection between NHS competition and existing national competition legislation, and, in doing so, clarifying and formalising the role of national competition authorities in the regulation of competition in the NHS.

Whilst the introduction of HSCA 2012 has caused a great deal of consternation and controversy (Timmins, 2012), much of this has centred on the perceived extension of the role of competition, particularly with reference to the secondary legislation of the Procurement, Patient Choice and Competition Regulations, which indicate that competitive procurement is to be preferred. However, the move from sector-specific regulation to competition law is also significant. HSCA 2012 marks a significant change in the status of the rules regarding competition concerning how and by whom those rules are to be interpreted and enforced. There are fears that exposing the NHS to competition law will result in a loss of control over decision making, resulting in decisions that are by default 'pro-competition', and do not consider the specifics of the NHS (Hudson, 2013; Toynbee, 2013). One school of thought is that the clarified legal framework put in place by HSCA 2012 may lead to the 'juridification' of the NHS quasi-market, where quasi judicial decisions replace ministerial and local discretion, as the logic of competition law dictates that parties act independently in accordance with the law (Davies, 2013). However, evidence relating to the introduction of competition legislation into areas previously subject to sector-specific competition regulation suggests that the change in mode of regulation can have minimal effect on the ground. Broadbent and Laughlin (1997) found that the changes resulting from the introduction of the National Health Services and Community Care Act of 1990 were 'absorbed' into the NHS without affecting the operation of the system. Stirton (2014), in exploring the transferable learning from the regulation of utilities in the United Kingdom to the implementation of HSCA 2012, suggested that sectoral regulators may continue to rely on sectoral rules rather than general competition powers.

This paper examines and compares the regulatory decisions taken in the sectorspecific regulatory regime preceding HSCA 2012 (January 2009-March 2013) and those decisions made in the period following the enactment of HSCA 2012 
(April 2013-August 2015). The analysis is based on an examination of all investigations conducted by the relevant regulatory bodies in response to potential infringements of the competition rules and highlights decisions where the rules were found to have been infringed. The aim of the analysis is to identify how the decisions were reached, the approach taken to weighing competition against other concerns, the influence of interested parties on decisions, the types of solutions that were deemed appropriate and the level of evidence required to satisfy the decisionmaking bodies. Clearly, there are many factors in addition to the regulation of competition that have changed between the two periods being examined such as the landscape of organisations planning and providing services, however, this paper focusses solely on the differences that can be related to the change from sector-specific regulation to a legislative framework. The paper does not discuss the interpretations of actors of HSCA 2012, although this is an important aspect of the impact of HSCA 2012 (see Allen et al., 2015). The paper argues that the regulation of competition has remained largely an internal matter for the NHS despite the increasing emphasis on the role of competition law and external regulators.

The paper first describes the rationale behind the introduction of competition regulation to the NHS and the development of the regulatory structures governing NHS competition. The second section of the paper details the decisions regarding the regulation of competition made by the Cooperation and Competition Panel (CCP) for NHS-funded services before HSCA 2012 was introduced, and decisions made after HSCA 2012 by Monitor and national competition authorities. The paper then compares the decisions taken under the two regimes to assess the extent to which the decisions differ.

\section{The regulation of NHS competition}

Whilst it is the regulation of competition rather than competition itself that is the subject of this paper, in order to understand the significance of the move from sector-specific regulation to a legislative approach it is necessary to provide some contextual information regarding the nature of the market in relation to health services generally and the English NHS specifically. The premise that competition would benefit the NHS has remained an important element of health policy in the English NHS since the early 1990s, and competition is thought to lead to improvements in efficiency, quality and responsiveness to consumers (Jones and Mays, 2009; Department of Health, 2010a). However, the effect of competition in the NHS has remained controversial (Bevan and Skellern, 2011; Office of Fair Trading, 2014). Due to the nature of health care services, such as asymmetry of information, specialist services, high entry costs and the need (in the United Kingdom) to ensure the fair delivery of services across the population, the market is acknowledged to be 'almost completely imperfect' (Olsen, 2009), and consequently the English NHS is subject to a quasi-market, in which the advantages of competition are combined with the retention of public funding. 
The development of the quasi-market in the English NHS in 1991 introduced a split between the purchasers of health services and the providers, where demand for services is managed by third-party commissioning bodies (currently Clinical Commissioning Groups (CCGs)), situated within the NHS hierarchy, acting on behalf of patients, and competition is used to allocate resources to the providers of services. There is not direct payment for services, and decisions about the allocation of resources are based on the consideration of the rights and needs of the collective, as well as those of the individual. There is a wide range of evidence demonstrating the hierarchical aspect of the NHS extends to the supply side despite incentives for competition (see Allen, 2013).

These factors are important for a discussion of competition regulation because of the argument that the NHS requires sector-specific regulation of competition due to the 'special' nature of the market in relation to health care, which also necessitates the creation of a 'quasi' rather than full market. Whilst the main objective of competition law is the maximisation of consumer welfare, sectorspecific regulation may have other objectives, which are balanced against the need to uphold and protect competition, such as the achievement of wider social goals. The introduction of legislation into such systems is thought to prevent, or reduce the influence of, the discretionary decisions of policy makers and sector-specific experts, which balance competition against other concerns, in favour of the 'rule of law' through the courts (Baldwin and Cave, 1999). Additionally, competition law tends to intervene when behaviour infringes the general principles, whereas sector-specific regulation takes a more prescriptive approach to expected behaviour (Baldwin and Cave, 1999), and there may be differences between sectorspecific regulation and legislation in the types of 'remedies' deemed acceptable to address breaches of competition rules (Buiges, 2006).

The rules affecting NHS competition and the arrangements for their enforcement are complex. The following provides an overview of the rules and enforcement authorities in place in the period in question, and an overview of the arrangements can also be found in Table 1 .

The quasi-market and accompanying regulatory mechanisms were first introduced to the English NHS in 1991, with the clear expectation that, regardless of the existing national and European laws regarding monopoly and anticompetitive behaviour, all matters would be managed internally by the Department of Health (1994) (Dawson, 1995). Despite a softening of the rhetoric about competition and markets, the New Labour government elected in 1997 continued with the purchaser/provider split (Allen, 2002), and from around 2002 onwards in a 'gradual, pragmatic' process (Mays et al., 2011), stimulated supply side competition through an increase in the diversity of providers of care and the freedom they had to act innovatively (Department of Health, 2002). The provision of NHS services was gradually opened up to a variety of accredited providers including both publicly owned and independent providers: most prominent was the establishment of Foundation Trusts (NHS bodies with a greater degree of autonomy, established under HSCA 2003), and the establishment in 2003 of 
Table 1. Competition rules and enforcing bodies (January 2009-August 2015)

\begin{tabular}{|c|c|c|c|c|c|c|c|c|c|}
\hline \multirow[b]{2}{*}{ Rules } & \multirow[b]{2}{*}{ Status } & \multirow[b]{2}{*}{ Applicability } & \multicolumn{7}{|c|}{ Enforcing body } \\
\hline & & & 2009 & 2010 & 2011 & 2012 & 2013 & 2014 & 2015 \\
\hline $\begin{array}{l}\text { UK and EU competition } \\
\text { law }\end{array}$ & Law & All 'undertakings' & \multicolumn{4}{|c|}{$\begin{array}{l}\text { The Office of Fair Trading } \\
\text { The Competition Commission Until March } 2014\end{array}$} & & \multicolumn{2}{|c|}{$\begin{array}{l}\text { The Competition and } \\
\text { Markets Authority } \\
\text { April } 2014 \text { onwards }\end{array}$} \\
\hline $\begin{array}{l}\text { The Principles and Rules } \\
\text { for Cooperation and } \\
\text { Competition }\end{array}$ & $\begin{array}{l}\text { Non-statutory NHS- } \\
\text { specific regulation }\end{array}$ & $\begin{array}{l}\text { Commissioners and } \\
\text { providers of NHS } \\
\text { services in England }\end{array}$ & \multicolumn{7}{|c|}{$\begin{array}{l}\text { The Cooperation and Competition Panel for } \\
\text { NHS-funded services Until March } 2013\end{array}$} \\
\hline $\begin{array}{l}\text { Health and Social Care } \\
\text { Act } 2012 \text { and } \\
\text { secondary legislation }\end{array}$ & Law & $\begin{array}{l}\text { Commissioners and } \\
\text { providers of NHS } \\
\text { services in England }\end{array}$ & \multicolumn{7}{|c|}{$\begin{array}{l}\text { Monitor (concurrent } \\
\text { responsibilities with bodies } \\
\text { enforcing competition law - see } \\
\text { above) April } 2013 \text { onwards }\end{array}$} \\
\hline
\end{tabular}

NHS = National Health Service. 
independent sector treatment centres to provide high volume, low-risk surgery to NHS patients. Patients were also offered choice between providers for their treatment, beginning with pilots of choice for cardiac surgery introduced in 2002 and culminating in the introduction of 'free' choice of any eligible provider at referral in 2008. New mechanisms to regulate competition were not developed until 2007 when the Principles and Rules for Cooperation and Competition ('Principles and Rules') were launched, administered from January 2009 by the CCP, a newly established body operating at arm's length from the Department of Health. It is notable that there was a significant lag between the Labour administration's stimulation of competition and the development of an accompanying regulatory framework, due perhaps to the gradual development of the market.

The Principles and Rules were based on the premise that both competition and cooperation were desirable, and they took other concerns into account in addition to competition. For example, decisions regarding mergers were not to be considered solely in relation to the protection of competition, but also in the light of patients' and taxpayers' interests in respect of matters such as whether the changes could 'deliver significant improvement in the quality of care' (Department of Health, 2010b). The CCP had no enforcement power. Its advice did not have any statutory basis and was not legally binding (CCP for NHS-Funded Services, 2009). It had a duty to investigate cases that might infringe the Principles and Rules and to make recommendations to the Secretary of State for Health and Monitor (at this stage the independent regulator of Foundation Trusts) in respect of Foundation Trusts, and the local Strategic Health Authority in respect of NHS Trusts, who would then decide what action would be taken.

This sector-specific competition regulation operated within the shadow of EU and UK competition law. The guidance concerning the role of the CCP acknowledged that the body did not replace the role and work of the national and European competition authorities (CCP for NHS-Funded Services, 2009), and that some of the conduct it investigated might also be subject to EU and UK competition law (CCP for NHS-Funded Services, 2010). The behaviour of any entity in the United Kingdom when engaging in economic activity is governed by the Competition Act 1998. When economic activity extends to the EU, the behaviour is governed by Articles 101 and 102 of the Treaty on the Functioning of the European Union (as amended by the Treaty of Lisbon 2007). This legislation regulates two aspects of behaviour to ensure that competition is not impaired. First, it prohibits anti-competitive behaviour, and second, it prohibits abuse of dominant market position. In the UK, in the period in question, competition law was enforced by the relevant national competition authorities: the Office of Fair Trading and the Competition Commission (until March 2014) (Competition Commission, Office of Fair Trading \& Monitor, 2014), and the Competition and Markets Authority (from April 2014). The Office of Fair Trading had responsibility for investigating suspected breaches of and enforcing the Competition Act in the United Kingdom. A further piece of legislation, the Enterprise Act 2002, 
specified that the Office of Fair Trading should refer merger investigations for a more detailed Phase II review to the Competition Commission where their initial investigations gave reason to believe that the merger may result in a substantial lessening of competition. The Competition Commission was responsible for ensuring healthy competition between businesses in the UK. From April 2014, both these functions were undertaken by the Competition and Markets Authority (see Table 1).

The applicability of national and European competition legislation to NHS activity before HSCA 2012 was an untested point (see Lear et al., 2010; Odudu, 2011). This is, at least partly, because the applicability of competition law hinges on the definition of an 'undertaking', which is carrying out economic activity in a market (Office of Fair Trading, 2011). Health services may be exempt from competition law, but this depends largely on definitions of solidarity and public service obligations. As the market in the NHS has developed, the applicability of national and European competition law has been increasingly called into question. However, importantly, in practice, until the changes of HSCA 2012, issues of competitive behaviour were dealt with internally by means of Department of Health rules and guidance.

HSCA 2012, which came into force in April 2013, made a direct correlation between competitive behaviour in the NHS and competition law (Den Exter and Guy, 2014), and has been seen as clarifying the previously unclear legal position, particularly with reference to merger control, rather than establishing a new system (Spencelayh and Dixon, 2014). The 'Principles and Rules' were subsumed and expressed as 'conditions' in the newly established 'provider licenses' and through secondary legislation [the Procurement, Patient Choice and Competition Regulations No. 2 (2013)]. Under the HSCA 2012, Monitor (as the new economic regulator for the whole of the NHS, not only Foundation Trusts) took over some of the functions of the former CCP and, along with the national competition authorities (i.e. the Competition and Markets Authority, and before that, the Office of Fair Trading and the Competition Commission), has powers to enforce competition law to prevent anti-competitive behaviour. Whereas the CCP was a non-statutory body, Monitor was given a statutory responsibility to prevent anti-competitive behaviour, which was against the interests of service users [HSCA 2012 s62 (3)], alongside duties to enable services to be integrated where this would improve quality, reduce inequality of access and reduce inequality of outcome, and not to cause a variation in the provision of services based on whether providers are public or private. Its responsibilities were clearly aligned with national competition authorities. Monitor has concurrent responsibilities with the Competition and Markets Authority in relation to anti-competitive agreements and abuse of dominant position (HSCA s 72). HSCA 2012 clarified that mergers involving one or more Foundation Trusts are subject to the Enterprise Act 2002 (HSCA s 79) and should be reviewed by the Competition and Markets Authority (formerly the Office of Fair Trading) with Monitor taking an advisory role in relation to the benefits of the merger for patients. Furthermore, the national competition authorities were also enabled to review all 
transactions involving a 'change of control', if turnover exceeds $£ 70$ million, such as joint ventures and acquisitions. Monitor on the other hand has sole responsibility for the examination of mergers between NHS Trusts.

A key mechanism in Monitor's regulatory responsibility under the HSCA 2012 is the provider license, which Monitor is responsible for issuing to all providers of NHS-funded services and which all providers require in order to provide NHS services (HSCA 2012 ss81-110). Conditions in the license relating to anti-competitive behaviour are intended to mirror the requirements of the Competition Act 1998 (Monitor, 2013).

Whilst HSCA 2012 made an explicit connection between the regulation of competition within the NHS and competition law, interestingly, the preceding sector-specific regulation through the enforcement of the 'Principles and Rules' sought to mirror the methods of evaluation used by the national competition authorities wherever possible. A recurring concept used by both the sector-specific regulator and the national competition authorities in relation to the evaluation of mergers is that of 'substantial lessening of competition', a term used in relation to a loss of rivalry between competing firms, which reduces competitive incentives to the likely detriment of customers. A substantial lessening of competition is one which is deemed to have a significant effect on rivalry over time, thereby reducing competitive pressure on firms. A key element of assessing mergers is therefore to establish the evidence on likely adverse effects.

The second concept of importance to both sector-specific competition regulation and competition law is the notion of remedies, remedial action to address a loss of competition and its effects. The aim of remedies in the view of the bodies interpreting competition law, is to restore the rivalry between firms, ideally by addressing the adverse effect at source. It is preferable to find a structural remedy which restores competition, rather than employ measures to regulate ongoing behaviour (Competition Commission, 2008).

Now that some time has elapsed since HSCA 2012 came into force in April 2013 , it is possible to examine the decisions that have been made in regard to the regulation of competition under the new regime in order to assess what, if any, material difference HSCA 2012 has made to the decisions being made about the regulation of competition.

\section{Analysis of decisions made regarding competition regulation}

\section{Decisions taken by the CCP (2009-2013)}

The CCP conducted investigations in relation to four areas: mergers, procurement cases, conduct cases and advertising disputes. ${ }^{1}$ Cases were assessed against the

1 Documents relating to all CCP decisions can be found at the National Archives website (http:// webarchive.nationalarchives.gov.uk/20140507021214/http://www.monitor.gov.uk/regulating-health-careproviders-commissioners/cooperation-and-competition/archive-co-operation-and-5). 
Table 2. Summary of reviews completed by Cooperation and Competition Panel (January 2009-March 2013)

\begin{tabular}{lcc}
\hline \hline Case area & $\begin{array}{c}\text { Number of cases } \\
\text { investigated }\end{array}$ & $\begin{array}{c}\text { Number found to be } \\
\text { inconsistent with 'Principles and Rules' }\end{array}$ \\
\hline Mergers & 54 & 7 \\
Procurement & 4 & 0 \\
Conduct & 11 & 5 \\
Advertising & 0 & 0 \\
\hline \hline
\end{tabular}

'Principles and Rules'. The reviews conducted by the CCP in its lifetime are summarised in Table 2.

\section{Merger decisions}

The majority of merger reviews focussed on compliance with Principle 5 of the 'Principles and Rules' which related to the promotion of patient choice of provider, and Principle 10 which related to the need to ensure that mergers were only permitted if there remained sufficient choice and competition or 'where they are otherwise in patients' and taxpayers' interest'(Department of Health, 2010b).

In the vast majority of merger cases that were found to be inconsistent with the 'Principles and Rules' the mergers were eventually approved, through the identification and agreement of 'remedies'. Remedies were proposed by the CCP after consultation with the merger parties, the commissioners and other local stakeholders, and put forward to the Secretary of State and/or NHS Trust Development Authority for agreement.

A number of merger cases are particularly noteworthy.

In one case, that of the proposed merger between the Nuffield Orthopaedic Centre NHS Trust and Oxford Radcliffe Hospitals NHS Trust, the CCP approved the case even though the merger would result in the loss of commissioner choice and competition in relation to routine elective orthopaedic services, as the benefits (including better services, private finance initiative costs savings and the optimisation of estate) were thought to outweigh the costs of the loss of competition. This is the only case in which a merger which was found to be detrimental to choice and competition was recommended for approval without the identification of remedies.

In other cases suitable remedies were identified. Some of these were structural. In the case of the proposed merger of Outer North East London Community Services and North East London NHS Foundation Trust, the CCP recommended the transfer of a particular service to the local Council in order to avoid a loss of competition in a particular service area. In the case of the merger of two mental health trusts in March 2011 (Norfolk and Waveney Mental Health NHS Foundation Trust and Suffolk Mental Health NHS Partnership Trust), a package of remedies was agreed including the retendering of a proportion of contracts. 
In other cases, behavioural remedies that regulated behaviour rather than addressed the inhibition of competition, were deemed acceptable.

First, in the case of the merger of Barts and the London School of Medicine and Dentistry, Newham University Hospital NHS Trust and Whipps Cross Hospital NHS Trust, the CCP found the merger was likely to incur a loss of patient choice and competition, but noted the presence of factors that took precedence over the need to ensure that choice and competition were preserved. These were that the commissioners were in favour of the merger and that a 'hostile' takeover by another party would not be practical. A set of behavioural remedies were agreed, including a requirement that the merger parties agree a set of quality indicators (such as quality visits by the commissioners, and commitment to achieving the claimed benefits of the merger), reflecting a higher quality than would be expected without the merger.

Three further mergers were also approved by the CCP subject to behavioural remedies (Lewisham Hospital NHS Trust with Lewisham Primary Care Trust (PCT) provider services arm, South Birmingham PCT, Heart of Birmingham PCT and Birmingham East and North PCT, Dartford and Gravesend NHS Trust and Medway NHS Foundation Trust), including the monitoring of the provision of choice of provider to patients by the merged organisation and the investigation of any lapses; compliance with the rules specifying how choice of provider should be offered to patients and the collection of evidence of this compliance; and the promotion of patient choice by commissioners and the measurement of service quality indicators with action to address decline, including retendering if necessary.

It appears that in the vast majority of cases the CCP merger recommendations were accepted. However, there were two occasions where the Secretary of State intervened: once (the proposed merger of Outer North East London Community Services and North East London NHS Foundation Trust), where the Secretary of State asked the merging parties to provide reassurance regarding the management of potential conflicts of interest occurring due to the General Practitioners' (GPs') role as both the provider and commissioner of services, and once in relation to the merger involving Barts (referred to above), where the Secretary of State altered one of the proposed remedies (Secretary of State for Health, 2012).

There was a single case where Monitor intervened after the CCP recommendation. In relation to the proposed merger of two mental health trusts [Norfolk and Waveney Mental Health NHS Foundation Trust and Suffolk Mental Health NHS Partnership Trust (referred to above)], the CCP was unable to identify any remedies to mitigate the adverse effects of the proposed merger and recommended that the merger should not occur. However, Monitor, upon presentation of new evidence regarding the benefits of the merger not considered by the CCP, decided that the merger should go ahead, on the grounds that it would be in patients' interests in relation to quality and safety and that remedies could be put in place to mitigate the loss of choice and competition (Monitor, 2011).

Two mergers were considered by Monitor under the 'Principles and Rules' as they commenced before HSCA 2012. One of these (the merger of parts of 
University Hospital Bristol NHS Foundation Trust and North Bristol NHS Trust) was found to be inconsistent with the 'Principles and Rules', but no action was taken as the merger had already taken place.

The analysis of these decisions reveal some important characteristics. First, other factors were considered in addition to the protection competition such as the benefits of mergers to services, financial issues in area and local support for proposals. Second, the ability of the Secretary of State for Health and Monitor to intervene in the judgements. Third, the use of both behavioural and structural remedies to mitigate for the loss of competition. It is also noteworthy that all proposed mergers proceeded.

\section{Procurement cases}

The CCP reviewed four procurement cases in response to complaints received. These related to procurement exercises conducted by NHS organisations, and were raised by independent sector organisations (NHS North of Tyne procurement appeal, Kings College Hospital Foundation Trust procurement appeal, Ashford and St Peters Hospitals NHS Foundation Trust procurement appeal, and Nottingham University Hospitals NHS Trust procurement appeal). All complaints related to alleged breaches of Principle 1, that commissioners must commission services from the providers best placed to deliver the need of their patients and populations and Principle 2, that commissioning and procurement must be transparent and non-discriminatory. The CCP decided that all four cases were within the range of reasonable decisions which could have been taken, and did not breach the 'Principles and Rules'. However, they noted that there were aspects of procurements which could have been improved, whilst not constituting a breach.

Two elements are of particular interest in relation to the procurement cases. First, the relatively small number of cases suggests either that procurement processes were understood and enacted very clearly, that issues were resolved locally, or that organisations had insufficient motivation to raise issues. Second, it is also noteworthy that all the complaints came from independent sector organisations.

\section{Conduct cases}

In total, 11 conduct cases were investigated, four of which were joint conduct and procurement cases. All complaints were made by independent sector organisations regarding the conduct of NHS organisations. The conduct provisions concerned the need for commissioners to act transparently, fairly and in a non-discriminatory manner, and for commissioners and providers to promote equality and ensure choice was not restricted against patients' interests. Conduct complaints were considered in relation to six principles within the 'Principles and Rules' (Department of Health, 2010b, Principles 1, 2, 3, 5, 6 and 8). Five conduct complaints were at least partially upheld.

In one of these, the Department of Health intervened in relation to the CCP judgement. The CCP found in 2009 that NHS Kingston (the PCT) had breached 
Principle 4 Rule 2 of the 'Principles and Rules' (December 2007 edition) (that the providers, referrers to and commissioners of NHS services must not restrict choice via collusive behaviour or any other action) when deciding not to let Churchill Medical Centre (a GP Medical Centre) provide NHS services from a new branch surgery, and recommended a structural remedy. It was reported that the Department of Health also carried out its own investigation before allowing the surgery to open (Health Service Journal, 2010).

In two cases, the CCP recommended behavioural remedies to be put in place to correct the future behaviour of organisations. In the first case, that of a complaint from Hanover Healthcare Ltd regarding commissioning practices by North West Specialised Commissioning Group, the remedies proposed by the CCP were to ensure future commissioning practices gave equality of opportunity and to publish on its website the details of the contracts the Specialised Commissioning Group had entered into. A second investigation into predatory pricing against York Hospitals NHS Trust and York PCT following a complaint by Assura East Riding LLP led to the finding that the PCT had acted inconsistently in relation to Principle 5 of the 'Principles and Rules', that commissioners and providers should encourage patient choice and ensure that patients have accurate and reliable information to exercise choice over health care. A behavioural remedy was proposed consisting of either the employment of an independent health care adviser to advise patients about choice, or that GPs make a record of patient choices.

In two further cases, that of Circle Health Ltd against Wiltshire PCT, and 3well Medical against Peterborough PCT, the CCP made recommendations of structural remedies, which would ensure that the commissioners changed their future commissioning practices and took steps to reverse their past mistakes. The complaint by 3 well Medical against Peterborough PCT was particularly interesting as a further example of the intervention of Ministers in the regulatory decisions. The complaint related to a conflicts of interest regarding the clinicians involved in decision making regarding the reconfiguration of primary and urgent care services in the Peterborough areas. The CCP recommended that an independent panel of clinicians review the case and that the PCT should put in place appropriate arrangements for the future management of conflicts of interest. Earl Howe, Parliamentary Under Secretary of State for Quality (Department of Health), intervened to disagree with the recommendation that the PCT seek advice from an independent panel of clinicians on the basis that this was not 'necessary or likely to materially affect the outcome' (Howe, 2012).

The decisions in relation to conduct cases are indicative of the trends in relation to the CCP decisions in other areas. The independent sector was the instigator of all complaints. This indicates that there is a degree of disquiet about the 'level playing field' between independent and NHS providers. There was a widespread use of remedies to mitigate for a loss of competition, and of particular note is the acceptance of behavioural remedies, which are thought weak in relation to competition law. Also of note is the continued intervention of Ministers, and the relatively small number of complaints which were considered. 
Table 3. Summary of reviews completed by regulatory bodies (April 2013-August 2015)

\begin{tabular}{llcc}
\hline \hline Case area & Decision-making body & $\begin{array}{c}\text { Number of cases } \\
\text { investigated }\end{array}$ & $\begin{array}{c}\text { Number inconsistent } \\
\text { with rules }\end{array}$ \\
\hline $\begin{array}{l}\text { Transactions } \\
\text { Mergers }\end{array}$ & Monitor (using 'Principles and Rules') & 2 & 1 \\
& Monitor & 1 & 0 \\
& Competition Commission & 1 & 1 \\
& Competition and Markets Authority & 1 & 0 \\
Acquisitions & Monitor & 1 & 0 \\
& Office of Fair Trading & 1 & 0 \\
Joint ventures & Office of Fair Trading & 2 & 0 \\
& Competition and Markets Authority & 1 & 0 \\
Commissioning & Monitor & 3 & 1 (1 case ongoing) \\
\hline \hline
\end{tabular}

\section{Competition regulation decisions made after April 2013}

The following section details the competition regulation decisions, which have been made under the new regime in the period April 2013-August 2015. ${ }^{2}$ While fewer cases have been reviewed under the new arrangements, which take place within a much shorter timeframe, these decisions show a decline in the acceptability of remedies as compensation for the loss of competition, and a higher threshold for the evidence base required for the acceptance of claimed benefits of transactions. There was also a decline in the ability of parties other than the regulatory body itself to affect decisions. The regulatory decisions taken during this period are detailed in Table 3.

\section{Transactions (mergers, acquisitions, joint ventures)}

In the 29-month period between April 2013 and August 2015, nine transactions were subject to scrutiny (five mergers, four acquisitions and two joint ventures). The first merger to be considered was the proposed merger of the Royal Bournemouth and Christchurch NHS Hospitals Foundation Trust with Poole Hospitals NHS Foundation Trust. In accordance with its responsibilities under HSCA 2012, Monitor reviewed the merger and advised the Office of Fair Trading in February 2013 that it was not satisfied that the benefits of the merger outweighed the loss of competition. The Office of Fair Trading referred the case to the Competition Commission in January 2013 for a more detailed Phase II review. In October 2013, the merger was rejected by the Competition Commission on the basis that it would reduce competition in the market.

The Competition Commission found that the proposed merger was likely to result in a significant lessening of competition in 55 clinical service areas, and

2 Documents detailing Monitor's decisions can be found at the UK Government website www.gov.uk (https://www.gov.uk/government/organisations/monitor). 
rejected the merger parties' arguments that the merger would result in customer benefits, which would outweigh the loss of competition, such as lower prices, higher quality or greater choice of services, or greater innovation. The reasons for the rejection of the suggested customer benefits included lack of detailed plans to support the claims, lack of commissioner support, and lack of evidence that (a) the benefits and savings would not occur irrespective of the merger and (b) the form some savings would take and lack of detailed implementation plans.

The only remedy the Competition Commission put forward was the prohibition of the merger. Interestingly, the merger parties cited earlier CCP recommendations regarding behavioural remedies in relation to mergers (as described above) and suggested a behavioural remedy (based on the NHS Friends and Family test) should be put in place, bolstered with retendering of contracts in the event of a drop in service quality. This proposed remedy was rejected by the Competition Commission, who cited not only problems with its effectiveness and appropriateness, but also expressed a lack of confidence in the capacity of a behavioural remedy to address such a wide ranging lessening of competition, and indeed in the suitability of behavioural remedies at all.

Following the rejection of the proposed merger by the Competition Commission, there appeared to be a move to avoid the escalation of merger proposals to the national competition regulators wherever possible. Monitor, the Office of Fair Trading and the Competition Commission issued a joint statement outlining work they would be undertaking to reduce number of mergers proceeding to formal review stage (Competition Commission et al., 2014), and Monitor contacted NHS Trusts outlining the aid they could offer to merger proposals to reduce the likelihood of Phase II review (Monitor, 2014a). Subsequently, Monitor published revised guidance regarding how it would engage with FTs at an early stage in the merger process (Monitor, 2014b), and how it would help FTs navigate any transactions with implications for the operation of competition (Monitor and Competition and Markets Authority, 2015).

Since this time, all mergers considered under the new regulations have been approved, together with four acquisitions involving NHS organisations, and two joint ventures both involving the merging of pathology services.

\section{Commissioning complaints}

In addition to the consideration of mergers, Monitor has responsibility for investigating complaints raised by anyone who thinks that a commissioner may breach, or has already breached, the Procurement, Patient Choice and Competition Regulations No. 2 (2013), the choice and competition elements of the NHS provider licence or the relevant elements of UK or EU competition law.

Two cases have been considered to date, one of which has been found to be inconsistent with the regulations. In the case of a complaint of alleged anticompetitive commissioner behaviour made by an independent sector provider, Spire Healthcare Group plc, in relation to the commissioning of elective services 
by Blackpool CCG and Fylde and Wyre CCG, the complaint was partially upheld. The complaint was that the actions of the CCGs had led to patients being directed away from Spire Fylde Coast Hospital and towards Blackpool Teaching Hospitals NHS Foundation Trust. Monitor rejected the claim that the commissioners were redirecting patients but did find that the CCGs had breached Standing Rule 39 (that the CCG should make arrangements to ensure that patients needing elective referral were given a choice of any clinically appropriate provider for the first outpatient appointment) and Standing Rule 42 (that CCGs should ensure the availability of choices was publicised and promoted to patients). Monitor accepted undertakings from the CCGs to give support to GPs in offering choice of provider to patients, and to check choices had been offered to patients.

A further commissioning complaint which was considered and rejected by Monitor was particularly interesting as it related to the interaction of competition, with the objective of increasing the integration of NHS services. The complainant, North Devon Healthcare NHS Trust, alleged that Northern, Eastern and Western Devon CCG had breached its regulatory obligations when it selected the Royal Devon and Exeter NHS Foundation Trust as the provider of complex adult services for the eastern part of the CCG area as it had not undergone a rigorous competitive procurement process, choosing instead to select a preferred provider and work with them to develop a detailed service proposal. The commissioner argued it had awarded the preferred provider status as the use of competitive processes would undermine the objective of increasing integration. In June 2015, Monitor made the provisional finding that the CCG did not breach the Procurement, Patient Choice and Competition Regulations by taking the preferred provider approach. However, Monitor made it clear that they would consider a further complaint if the CCG did not undergo a rigorous due diligence process to ensure that the selected provider would provide value for money.

\section{Challenges not involving regulators}

Evidence of the threat of legal proceedings has been found in three instances since April 2013 (Health Service Journal, 2014a). All three challenges have since been discontinued.

\section{Discussion}

The foregoing analysis indicates HSCA 2012 has had a very mixed impact on the decisions being made regarding the operation of competition in the English NHS.

On one hand, there is a clear difference in the type of decisions made by the sector-specific regime of the CCP and the 'Principles and Rules', and the regime of Monitor and the national competition authorities following HSCA 2012. Whilst the two regimes were tasked with upholding similar rules regarding competition, and indeed followed similar frameworks and processes when making their 
decisions, there was a difference in the regulatory bodies' interpretation of the rules, and of the standards they employed when evaluating the cases brought before them. As the sector-specific regulator, the CCP's decisions indicate a desire to weigh the impact of a loss of competition and the need to promote competition against other concerns relevant to the provision of health services, such as the need to achieve good quality services and value for money. Indeed, the acceptance of the CCP of a wide range of remedies to compensate for a loss of competition, and a willingness to weigh other factors above the need for competition, reflects a belief that at times, patients' interests are best served in arrangements other than competition. Meanwhile, the case of the failed Bournemouth/Poole merger shows the impact of competition law and national competition authorities on the decisionmaking process, reflected by the need, under competition law, to value and promote competition above all other concerns. Indeed, whilst Monitor, the Secretary of State for Health (BMJ, 2014) and the House of Commons Select Committee (House of Commons Health Committee, 2014, para 93) all suggested that the decision to prevent the merger was not in the interest of the NHS overall, they were powerless to exert any influence over the decision made. The risks of this process are that first, the decisions being made do not recognise the variety of aims of NHS services, not all of which can be addressed by market mechanisms, and also that second, the cost to the NHS of meeting the increased requirements for the provision of evidence to satisfy the requirements of the national competition bodies may be exorbitant. This situation reflects the concerns voiced by Davies (2013), that the process of juridification caused by HSCA 2012 would result in a situation in which judicial decisions would replace ministerial and local discretion, culminating, she suggests, in a lack of accountability.

On the other hand, however, the other cases considered under the regime after HSCA 2012 suggest that, following the failed Bournemouth/Poole merger, the NHS is avoiding entanglement with competition law. This has resonance with the experience reported from other sectors and previous NHS reform, which suggests that whilst there is certainly the potential, as in the case of Bournemouth and Poole, for a loss of ministerial and local discretion, sector regulators continue to rely on sectoral rules despite the clear remit of competition law (Broadbent and Laughlin, 1997; Stirton, 2014). Monitor has adopted the role of a 'translator' between the NHS and competition authorities in relation to mergers, to allow mergers to progress 'without falling foul of the competition authorities' (Health Service Journal, 2014b). The small number of commissioning and procurement cases considered under both regimes, suggests that there may be a long-standing practice to resolve matters informally where possible (even avoiding sector-specific regulation). Monitor reports having received 166 enquiries about the regulations from April 2013 to March 2014 (Health Service Journal, 2014a), the vast majority of which have been resolved without a formal investigation or using enforcement powers. Worryingly, it has been suggested that merger proposals are being entirely abandoned due to concerns about the assessment process (Health Service Journal, 2013). 
The sustainability of this retreat from the new regulatory regime is questionable though. It is notable that the independent sector was commonly the instigator of complaints regarding competitive practices, and they are, of course, unlikely to be dissuaded from this course of action in the future by concerns regarding the implications of competition law for the NHS. Whilst the vision of the most recent NHS strategy document 'Five Year Forward View' is notable because of the lack of any mention of competition or the market (NHS England, 2014), the regime introduced by HSCA 2012 cannot easily be reversed. The discrepancy between the need to protect competition upheld by HSCA 2012, and the emphasis in emerging strategy on the need for local health economies to collaborate and indeed merge seems to open the door for further complaints from the independent sector, should they so wish. A further potentially interesting development, and the subject of much speculation (Reynolds and McKee, 2015), is the development of the Transatlantic Trade and Investment Partnership, which is a planned trade pact between the EU and the United States. Whilst the wording of the pact has not yet been agreed, and therefore its impact on NHS health care is not known, it is possible that the agreement will open up the NHS market to American companies, further increasing the likelihood that the NHS will be exposed to assessment in relation to competition law in the future.

\section{Acknowledgements}

This report is independent research arising from a Doctoral Research Fellowship supported by the National Institute for Health Research. Part of the study was funded by the Department of Health via its Policy Research Programme. It formed part of the work programme of the Policy Research Unit on Commissioning and the Healthcare System. The views expressed here are those of the researchers and do not reflect the position of the NHS, the National Institute for Health Research or the Department of Health.

\section{References}

Allen, P. (2002), 'Plus ca change, plus c'est la meme chose: to the internal market and back in the British National Health Service', Applied Health Economics and Health Policy, 1(4): 171-178.

Allen, P. (2013), 'An economic analysis of the limits of market based reforms in the English NHS', BMC Health Services Research, 13(Supplement 1): S1.

Allen, P., D. Osipovic, E. Shepherd, A. Coleman, N. Perkins and E. Garnett (2015), 'Commissioning Through Competition and Cooperation', Final Report to the Department of Health, London: PRUComm.

Baldwin, R. and M. Cave (1999), Understanding Regulation, Oxford: Oxford University Press.

Bevan, G. and M. Skellern (2011), 'Does competition between hospitals improve clinical quality? A review of evidence from two eras of competition in the English NHS', British Medical Journal, 343: d6470. 
BMJ (2014), Competition rules may need to be applied differently to healthcare, says Hunt. 348: g2082.

Broadbent, J. and R. Laughlin (1997), 'Contracts, Competition, and Accounting in Health and Education: An Example of Juridification at Work?', in S. Deakin and J. Michie (eds), Contracts, Co-operation, and Competition: Studies in Economics, Management and Law, Oxford: Oxford University Press, 214-252.

Buiges, P. A. (2006), 'Competition Policy Versus Sector-Specific Regulation in Network Industries - The EU Experience', UNCTAD's Seventh Session of the Intergovernmental Group of Experts on Competition Law and Policy, Geneva.

Competition Commission (2008), 'Merger Remedies. Competition Commission Guidelines', London: Competition Commission.

Competition Commission, Office of Fair Trading \& Monitor (2014), 'Ensuring that Patients' Interests are at the Heart of Assessing Public Hospital Mergers', Joint Statement, 17 October 2013.

Cooperation \& Competition Panel (CCP) for NHS-Funded Services (2009), 'Memorandum of Understanding Between the DH/Monitor and the Cooperation and Competition Panel', London: Cooperation and Competition Panel.

Cooperation \& Competition Panel for NHS-Funded Services (2010), Conduct Guidelines, London: Cooperation and Competition Panel.

Davies, A. C. L. (2013), 'This time, it's for real: the Health and Social Care Act 2012', The Modern Law Review, 76: 564-588.

Dawson, D. (1995), Regulating Competition in the NHS: The Department of Health Guide in Mergers and Anti-Competitive Behaviour, York: University of York.

Den Exter, A. P. and M. Guy (2014), 'Market Competition in Health Care Markets in the Netherlands: Some Lessons for England?', Medical Law Review, 22: 255-273.

Department of Health (1994), 'A Guide to the Operation of the NHS Internal Market', London: Department of Health.

Department of Health (2002), Delivering the NHS Plan: Next Steps on Investment, Next Steps on Reform, London: Department of Health.

Department of Health (2010a), 'Equity and Excellence: Liberating the NHS', White Paper, Department of Health, London.

Department of Health (2010b), 'Principles and Rules for Cooperation and Competition', July, London, Department of Health.

Health Service Journal (2010), 'Disputed Branch Surgery gets go ahead from Government' www.hsj.co.uk/disputed-branch-surgery-gets-go-ahead-from-government/5013396.article [27 August 2015].

Health Service Journal (2013), 'Trust Super Merger Shelved' http://www.hsj.co.uk/acute-care/ trust-super-merger-shelved/5066110.article [27 August 2015].

Health Service Journal (2014a), 'Analysis: Increase in Procurement and Competition Challenges', www.hsj.co.uk/commissioning/analysis-increase-in-procurement-and-competition-challenges/ 5068560.article [27 August 2015].

Health Service Journal (2014b), 'Bennett sets out new approach for merger and failure', www.hsj.co.uk/5067310.article [27 August 2015].

House of Commons Health Committee (2014), 'Public Expenditure on Health and Social Care', London: House of Commons Health Committee.

Howe, E. (2012), 'RE: Letter from Earl Howe to Maureen Donnelly', March 2012, Type to PETERBOROUGH, N. C. A. 
Hudson, B. (2013), 'Competition and Collaboration in the "New NHS”, Centre for Health and the Public Interest.

Jones, L. and N. Mays (2009), Systematic Review of the Impact of Patient Choice of Provider in the English NHS, London: London School of Hygiene and Tropical Medicine.

Lear, J., E. Mossialos and B. Karl (2010), 'EU Competition Law and Health Policy', in E. Mossialos, G. Permanand, R. Baeten and T. Hervey (eds), Health Systems Governance in Europe: The Role of European Union Law and Policy, Cambridge: Cambridge University Press, 337-378.

Mays, N., A. Dixon and L. Jones (eds), (2011), Understanding New Labour's Market Reforms of the English NHS, London: The King's Fund.

Monitor (2011), 'Minutes of a Special Meeting of the Monitor Board', 11 October.

Monitor (2013), The New NHS Provider Licence, London: Monitor.

Monitor (2014a), 'Letter from Monitor to all NHS Trusts and Foundation Trusts: Arrangements to Support NHS Foundation Trusts Contemplating Mergers', 24 January https:// www.gov.uk/government/uploads/system/uploads/attachment_data/file/288918/Letter_ from_David_Bennett_on_mergers_24_January_2014.pdf [27 August 2015].

Monitor (2014b), 'Our New Approach to Transactions: Consultation Responses and Next Steps', London: Monitor.

Monitor \& Competition and Markets Authority (2015), Competition Review of NHS Mergers. A Short Guide for Managers of NHS Providers, London: Monitor.

NHS England (2014), Five Year Forward View, London: NHS England.

Odudu, O. (2011), 'Are state-owned health-care providers undertakings subject to competition law?', ECLR, 32: 231-241.

Office of Fair Trading (2011), Public Bodies and Competition Law-A Guide to the Application of the Competition Act 1998, London: Office of Fair Trading.

Office of Fair Trading (2014), Competing on Quality-Literature Review, London: Office of Fair Trading.

Olsen, J. A. (2009), Principles in Health Economics and Policy, Oxford: Oxford University Press.

Reynolds, L. and M. Mckee (2015), 'Is the NHS really safe from international trade agreements?', BMJ, 350: h2179. www.theguardian.com/commentisfree/2013/nov/15/competition-killingnhs-bournemouth-poole [27 August 2015].

Secretary of State For Health (2012), 'Letter from Secretary of State for Health to Professor M Spyer', March, Chair of NHS London.

Spencelayh, E. and J. Dixon (2014), Mergers in the NHS: Lessons from the Decision to Block the Proposed Merger of Hospitals in Bournemouth and Poole, London: The Health Foundation.

Stirton, L. (2014), 'Back to the future? Lessons on the pro-competitive regulation of health services', Medical Law Review, 22: 180-199.

Timmins, N. (2012), Never Again? The Story of the Health and Social Care Act 2012, London: The King's Fund and Institute for Government.

Toynbee, P. (2013), 'Competition is Killing the NHS, for No Good Reason but Ideology', The Guardian. www.theguardian.com/commentisfree/2013/nov/15/competition-killing-nhsbournemouth-poole. 